\title{
The extent of the pterosaur flight membrane
}

\author{
Ross A. Elgin, David W.E. Hone, and Eberhard Frey \\ Acta Palaeontologica Polonica 56 (1), 2011: 99-111 doi: http://dx.doi.org/10.4202/app.2009.0145
}

The shape and extent of the membranous brachioptagium in pterosaurs remains a controversial topic for those attempting to determine the aerodynamic performance of the first vertebrate fliers. Various arguments in favour of the trailing edge terminating against either the torso or hip, the femur, the ankle, or different locations for various taxa, has resulted in several published reconstructions. Uncertainty over the correct model is detrimental to both aerodynamic and palaeoecological studies that are forced to simultaneously consider multiple and highly variable configurations for individual taxa. A review of relevant pterosaur specimens with preserved soft tissues or impressions of the wing membrane, however, strongly suggests that the trailing edge of the wing extended down to the lower leg or ankle in all specimens where the brachiopatagium is completely preserved. This configuration is seen across a phylogenetically broad range of pterosaurs and is thus likely to have been universally present throughout the Pterosauria. Support for opposing hypotheses where the trailing edge terminates against the body, hip, or knee are based on several specimens where the wing membrane is either incomplete or has undergone post-mortem contraction. An ankle attachment does not rule out a high aspect ratio wing as the curvature of the trailing edge and the ratio of the fore to hind limbs also play a major role in determining the final shape of the membrane.

Key words: Reptilia, Pterosauria, flight, wings, patagium, Mesozoic.

Ross A. Elgin [rosselgin@hotmail.com], Eberhard Frey [innofrey@aol.com], Staatliches Museum für Naturkunde Karlsruhe (SMNK), Erbprinzenstraße. 13., 76133 Karlsruhe, Germany; David W.E. Hone [dhone@ivpp.ac.cn], Institute of Vertebrate Palaeontology and Palaeoanthropology (IVPP), Xizhimenwai Dajie 142, Beijing 100044, P. R. China.

This is an open-access article distributed under the terms of the Creative Commons Attribution License (for details please see creativecommons.org), which permits unrestricted use, distribution, and reproduction in any medium, provided the original author and source are credited. 
Fof Full text $(720.8 \mathrm{kB})$ 